\title{
Dynamic Assessment in Education: A Case-Study of Chinese-Speaking EFL Classroom
}

\author{
Hind Al Fadda ${ }^{1}$, Muhammad Afzaal ${ }^{2,3, *}$, Phillip J. Haberman ${ }^{4}$ \\ ${ }^{1}$ College of Education, King Saud University, Saudi Arabia \\ ${ }^{2}$ Department of English, Foundation University Islamabad (Rawalpindi Campus), Pakistan \\ ${ }^{3}$ Shanghai International Studies University, China \\ ${ }^{4}$ Shanghai Jiao Tong University, China
}

Received August 4, 2020; Revised November 15, 2020; Accepted November 29, 2020

\section{Cite This Paper in the following Citation Styles}

(a): [1] Hind Al Fadda, Muhammad Afzaal, Phillip J. Haberman, "Dynamic Assessment in Education: A Case-Study of Chinese-Speaking EFL Classroom," Universal Journal of Educational Research, Vol. 8, No. 12, pp. 6967 - 6977, 2020. DOI: 10.13189/ujer.2020.081264.

(b): Hind Al Fadda, Muhammad Afzaal, Phillip J. Haberman (2020). Dynamic Assessment in Education: A Case-Study of Chinese-Speaking EFL Classroom. Universal Journal of Educational Research, 8(12), 6967 - 6977. DOI: 10.13189/ujer.2020.081264.

Copyright $\bigcirc 2020$ by authors, all rights reserved. Authors agree that this article remains permanently open access under the terms of the Creative Commons Attribution License 4.0 International License

\begin{abstract}
This paper reports on the use of dynamic assessment (DA) by an English as second language teacher (ESL) in their classroom in China. It examines how DA can be employed in English as foreign language classrooms as a method of developing learners' oral English skills. DA is framework with the aim of combing both instruction and assessment in a way which supports development (Poehner, 2008). It is founded in the ideas of Vygotsky's (1987) zone of proximal development (ZPD) emanating from his socio-cultural theory (SCT). ZPD highlights the role of a more capable others as mediators who interact learners in order to help them realize their potential. This study provides an example of how an EFL teacher might utilize DA in their classroom based on their personal understanding and with interpretation of it. Examples of the interactions between the teacher and learners are analyzed in this study to find out investigate how it they aid in development.
\end{abstract}

Keywords Dynamic Assessment, Zone of Proximal Development, Socio-Cultural Theory, English Learners, Education, China

\section{Introduction}

The foundation of dynamic assessment (DA) is built upon Russian psychologist Lev Vygotsky's zone of proximal development (ZPD). In essence, the ZPD is the area between what a learner can do and cannot do without assistance from a more knowledgeable other (MKO) such as a peer or teacher. In other words, the ZPD is what a learner can do with guidance from an MKO. An important part of ZPD is the role of mediating interactions between a learner and an MKO, (Lantolf and Poehner, 2004). These interactions between learner and MKO, result in the development of a higher thinking capacity in the learner (Lantolf and Poehner, 2004). DA focuses specifically on these interactions between a learner and MKO and the role they play in the development of a learner's higher thinking capacity (Infante and Poehner, 2016).

DA is one possible method to support the development of second language learners (L2ers) L2 ability, particularly concerning speaking ability, given that DA it is interactive by nature, according to Son and Kim (2017). Some scholars have pointed out that language for communicative purposes is the main objective of language learning given that speaking is the primary way by which human beings communicate with one another (Lazarton, 2001). Others, such as Brown (2001) assert that overall speaking skills can be divided into various sub-skills, such as the grammar, which the current study explores in more depth.

There are many studies which investigate writing (Shrestha and Coffin, 2012), reading (Kozulin and Garb, 2002), listening (Hidri, 2014), Afzaal \& Xiangyi (2020), 
acdemic reading and writing and speaking skills (Hill and Sabet, 2009). However, very few studies have investigated DA in the context of one of the world's largest English language learning environments, China. Several studies have been carried-out in the context of Chinese-speaking English learners, however, the participants were adult learners (Miao and Lu, 2012; Wang, 2015; Qian and Yang, 2017). Furthermore, these studies investigated writing (Miao and Lu, 2013), reading (Qian and Yang, 2017) and listening (Wang, 2015). None of them examined speaking skills in child-learner L2 contexts. The motivation of this study is driven by this gap in the literature.

\section{Theoretical Background}

\subsection{Socio-Cultural Theory (SCT)}

SCT in second language acquisition (SLA) seeks to explain the developmental process of L2ers and views teachers and learners as equal contributors to the development of cognitive systems (Anning et al., 2008). SCT, proposed by Vygotsky, is focused on the cognitive processes of human beings, which includes language acquisition. After his death, Vygotsky's work was furthered by scholars such as Lantolf, Donato, Thorne, Pavlenko, Swain and Lapkin (Lantolf, 2000b). These and others scholars took SCT and used it as a lens through which to view SLA by exploring how interactions between speakers contributes to the acquisition of language. The central pillar of SCT is that interactions between members of society are a key cause of the development of cognitive ability (including language). According to Lantolf and Thorn (2006a), "while human neurobiology is a necessary condition for higher order thinking, the most important forms of human cognitive activity develop through interaction within social and material environments". Social environments may include family, peers, and socially organized events such as education and sports. In SCT, the development of cognitive skills is highly connected to involvement in these spheres of life.

\subsection{Zone of Proximal Development (ZPD)}

A key idea within SCT is the zone of proximal development (ZPD). ZPD can be characterized as "the distance between the actual developmental level as determined by independent problem solving and the level of potential development as determined through problem solving under adult guidance or in collaboration with more capable peers" (Vygotsky, 1978). Essentially, a child's ability to perform successfully on a task may be increased with proper assistance from a teacher or peer. ZPD is a space between an individual's current and potential ability and can be developed through interaction with mediators in their environment, such as a teacher or peer (Lightbrown and Spada, 2006). The skills learned in the ZPD through interaction with an MKO may eventually be convertible for independent reproduction by the learner in future interactions. To sum up, the ZPD, is the area between actual and potential ability, and therefore requires intervention on behalf of a teacher or peer to reach that potential. Thus, mediators (e.g. teachers) must play an important role if L2ers are to realize their full potential in the domain of $\mathrm{L} 2$ acquisition.

\subsection{Dynamic Assessment (DA)}

Although DA is rooted in Vygotsky's ZPD, it's advancement as an important theory of SLA can be attributed to two other scholars, Luria and Feuerstein (Leung, 2007; Poehner, 2007; Poehner and Lantolf, 2005). As mentioned above, a key tenant of ZPD, is the mediator. As we know, ZPD is the zone between what learners are capable of on their own and what it is possible for them to achieve with help from a teacher or MKO. As a result of the interactions that occur in the ZPD and are mediated by an $\mathrm{MKO}$, a learner's cognitive functioning may reach a higher level. In other words, mediation by someone such as a teacher plays a central role in a learner's interaction with their environment, and thus in their language development. In light of this discussion, DA is not only focused on a final product, but rather the learner's development. Poehner and Lantolf (2004) also assert the idea that in DA development is the focal point, whereas with non-DA based techniques, a learner's performance is the focal point. I summary, DA is an interactive process of assessment in which the level of mediation fluctuates based on what is required to facilitate growth in the learner (Aliaafreah and Lantolf, 1994).

\subsection{Praxis}

As seen above, a focus on development and change run through many aspects of Vygotskian theory. According to Vygotsky (1997), the purpose of a theory is ability to promote change in the universe, not its ability to explain it. As a result, his work emphasizes the developmental processes of the human mind, instead of just describe how it functions. Especially important to Vygotsky was the role of society and culture in the development of human cognition. Therefore, his work paid special attention to the practical application of ideas which encourage development and change. He is therefore considered to be a proponent of 'praxis', in which theory and practice operate in an interdependent relationship; that is, theory lays a foundation for practice and practice in turn helps mold theory.

\section{Previous Studies on DA}

Bearing in mind that DA is a means of aiding the development of L2ers, several studies have been carried out examining the role and impact of DA in English as a 
second language (ESL) environments. Studies on writing, reading, listening, and speaking skills have all been conducted (Shrestha and Coffin, 2012; Kozulin and Garb, 2002; Hidri, 2014; Hill and Sabet, 2009). There have also been various studies on DA in the context of English language learning in the booming English education market of China. The majority of these study have focused on adult L2ers (Miao and Lu, 2013; Wang, 2015; Qian and Yang, 2017) and investigated writing, reading, and listening skills.

While numerous studies on DA have been conducted, they have mostly taken place in lab-like environments with participants completing well-thought out tasks in hopes of showing a cause and effect relationship between DA and L2er development. Although this methodology is useful, it is not always possible to carry out such experiments in real-world classroom settings where conditions are not always controllable (i.e. time limitations, curriculum, classroom interruptions, varying abilities and motivations, and the presence of multiple MKOs (e.g. other students).

The lack of studies focusing on DA in real-life classrooms, along with the aforementioned concept of 'praxis', i.e. the application of theory for bringing about change, is the inspiration of the current study. This, paired with the apparent dearth of DA research on child L2ers in China make up the underlying motivation of this study, which is to provide insight into the application of DA in an EFL / ESL classrooms.

\section{The Current Study}

\subsection{Comparison and Contrast Previous Studies}

The current study does not follow the same methodology as most DA-related L2 research, but rather more closely resembles Lantolf and Poehner's (2010) paper which saw an elementary school L2 Spanish teacher in the United States employ her own DA-based strategy in her L2 classroom. In their study, the teacher followed an interventionist approach by using a list of eight teacher prompts. The eight prompts are on a scale of most implicit (e.g. requiring the least amount of assistance from the teacher as possible) to most explicit (e.g. requiring the most assistance from the teacher as possible). The table, also used in the present study, can be seen in Figure 1 below.

It is important to note that Lantolf and Poehner's (2010) study was not an experimental one in which highly controlled tasks were implemented in a lab-like setting to discover the effects of DA. Rather it was a real-world example of its application highlighting that, "DA is not a pre specified technique or method of assessing that must be followed in a prescribed manner, but in fact is a way of reconceptualizing the relationship between teaching, assessment and development" (Lantolf and Poehner, 2010).

This paper follows the example of Lantolf and Poehner (2010) which is a case-study focusing on the the implementation of DA in a second language classroom. In addition, unlike Lantolf and Poehner's (2010) study, it analyzes the development of four learners' acquisition of past-tense verb rse of three weeks. There are a few key differences between their study and the current study. Firstly, while in the former study the teacher spent a limited amount of time -15 minutes - with the students per session, the participants in this study attended 3 separate 1.5 -hour sessions. Although the part of the lesson in which the target structure and the

teacher prompts listed above were utilized only lasted a few minutes, the total time of exposure to English per session was approximately 4.5 hours. Secondly, the L1 and target-language of the studies were different, the former Spanish, the latter English. Thirdly, the major analysis portion of earlier study mostly focused on detailing the interaction between the teacher and students. Meanwhile, this study not only focuses on the interactions, but also how the students' control over the target-structure developed over the course of three weekly sessions.

1. Pause

2. Repeat the whole phrase questioningly

3. Repeat just the part of the sentence with the error

4. Teacher points out that there is som ething wrong with the sentence. Alternatively, can be posed as a question, "What is wrong with that sentence?"

5. Teacher points out the incorrect word

6. Teacher asks either/or question (e.g. go or went?)

7. Teacher identifies the correct answer

8. Teacher explains why 


\begin{tabular}{|l|l|l|l|}
\hline Name & $\begin{array}{l}\text { INTRCT. 1 } \\
\text { (session 1) }\end{array}$ & INTRCT. 2 & INTRCT. 3 \\
\hline Conner & $5^{*}$ watch / watched & & \\
\hline Ginny & $2^{*}$ do / did & & \\
\hline Jack & $6^{*}$ go $/$ went & & \\
\hline Mary & $6^{*}$ write / wrote & & \\
\hline
\end{tabular}

Figure 2. Interaction Grid (pseudonyms in place of students' real name

The present study employed a similar interaction grid found in Lantolf and Poehner's (2010) study; as seen in table 1. In the table 1, the numbers to the right of the student's pseudonyms under INTRCT. 1 coincide with the level of teacher intervention needed during the session. For example, the 2 means that in order for Ginny to produce the correct form of the past-tense verb watch (watched), the teacher had to intervene by repeating the whole phrase questioningly, whereas for Jack, in order to produce the correct past-tense form of go (went), a level 6 intervention was required indicating that the teacher pose a yes or no question to elicit the correct response. Next to the number indicating the intervention level there is an asterisk denoting the incorrect form initially used by the participant; followed by the correct form produced after intervention from the teacher. For instance, in INTRCT 1., Ginny first say $d o$, then after a level 2 intervention by the teacher, she produced the correct past-tense form $\mathrm{did}$.

\subsection{Aim and Motivation}

As mentioned earlier, the motivation of this study comes from the gap in research investigating DA in the context of child-learner EFL classrooms. This study tries to fill this gap by examining the use of DA an EFL classroom in Shanghai, China with four Chinese-speaking child L2ers. There are two major aims of this study. The first aim is to see how an ESL teacher in China uses DA in a normal (e.g. non-experimental) classroom environment. The second aim is to examine the development of the learners' acquisition of the target-structure, past-tense verb forms. Past tense verbs in English are typically classified as either regular or irregular. Regular verbs follow a generalized rule of adding -ed (e.g. worked, played, kicked). In contrast, irregular verbs do not follow a specific pattern as such (e.g. see and saw, go and went). Mandarin Chinese, in contrast, does not have tense markers, but rather uses discourse markers to indicate time which is significant because the participants of the current study are Mandarin Chinese ( $\mathrm{Li}$ and Thompson, 1989). It is worthwhile to mention that this study takes place in normal (e.g. non-experimental) classroom environment. Therefore, there is no control group or manipulation of variables. As discussed, a major goal is to show how DA can be implemented into an actual classroom, not explore cause and effect relationships. With this in mind, the next section discusses the methodology used to carry out the present study.

\section{Methodology}

\subsection{Participants}

Although the study took place in a real-world classroom, the students in this study are referred to as participants. Four second grade students ( 2 female, 2 male, all age 7) are included in the study. They all speak Mandarin Chinese as their L1 and attend a primary school in Shanghai, China, where they live. At the time of the study, the participants had studied English with the same teacher, a native English-speaker from the United States, for 1.5 hours per week over the last 2 years. Although no formal English level-assessment test was given to the participants, according to the teacher's knowledge of their overall English abilities (speaking, reading, writing, and listening), Ginny has the highest overall level, followed by Conner, and finally, Jack and Mary, who display the lowest overall level.

\subsection{Materials}

Materials for the study include: 1) The list of eight teacher prompts in Figure 1 to provide consistency in the quality and quantity of feedback given to all participants, across all interactions, during all sessions. This kind of consistency not only aids the teacher by allowing them to seamlessly incorporate DA into the class, but also allows the level of intervention needed by the teacher to be accurately tracked throughout the entire length of study. 2) The interaction grid in Figure 2 used to record the level of intervention $(0-8)$ needed in order for the learner to arrive at the correct past-tense verb form (the target-structure in 
the study). The interaction grid also includes an area for the teacher to make notes about the type of error made by the participants as well as any additional comments. 3) In order to analyze a full conversation, session 3 was recorded on a hand-held recording device. The audio recording was transcribed using web-based transcription software and then manually checked by the researcher for accuracy. Because the focus of the study is on the oral production (as opposed to written) of correct past-tense verb forms, the participants did not directly interact with any materials during the sessions.

\subsection{Tasks}

As mentioned earlier, this study did not incorporate controlled tasks aimed at manipulating certain variables with the objective of showing a causal relationship between the use of DA and L2 ability. Rather, its purpose is to show how DA may be implemented into an L2 classroom, while at the same time providing insight about progress in language development made by the L2ers during the DA interactive sessions. To reiterate, this study does not seek to show how effective use of DA causes an improvement in L2 ability, but rather show a possible way that DA can be used in the L2 classroom. With this in mind, the task given to the participants was posed as a question at the beginning of the session. In session 1 the teacher wrote "What did you do yesterday?" on the whiteboard then proceeded to ask each student the question. In session 2, the question was altered to "What did you do last week?", and in the final session, the question from session one was repeated. The reason for altering the question in session 2 was an attempt to limit repetition of the same answer used in previous sessions. In addition, because the sessions took place on a Monday afternoon, the 'yesterday' question would cause the learner to rEflect on Sunday, while the 'last week' question would cause them to consider what they had done for the past 7 days. It is assumed that while the participants weekday schedule would include a repetition of many activities (i.e. wake up, go to school, do homework), their weekend schedule would invariably include a wider variety of activities (play with friends, go to the park, watch TV). Therefore, including the 'yesterday' and 'last week' questions provided the benefit of giving the learner more available responses, resulting in a lesser likelihood of repeated responses. In other words, it is thought by the researcher that one week between sessions should provide enough time to limit memory effect as well as provide opportunity for actual events to occur in the participants' lives which can be shared in their responses.

\subsection{Procedure}

The procedure for each interaction session was the same.
All four participants were present in the session at the time. Each session began with the teacher writing the question on the whiteboard, "What did you do yesterday?" in sessions 1 and 3, "What did you do last week?" in session 2. Next, the teacher asked each participant the question orally. Steps were taken in an attempt to minimize the effect of the order the participants were asked in. To prevent participants from copying each other's answers, in each session they were asked in a different order. In session 1, Conner was asked first, followed by Jack, then Mary, and lastly Ginny. In session 2, Ginny was asked first, next Mary, then Jack, and last Conner. In the last session, Conner was asked, then Mary, followed by Ginny, and then Jack. Prior to asking questions, the other participants were instructed not to interrupt or help their classmates with their responses. As the participants responded, the teacher intervened following the first (and least explicit) prompt from list of 8 teacher prompts in Figure 1. For example, after an incorrect response, the teacher would first pause (level 1 prompt), if the participant still did not produce the correct response then the teacher would repeat the whole phrase questioningly (level 2 prompt). This process would continue until the correct answer was given. During interactions, the teacher made notes as to the type of error made and level of intervention was required. Only one interaction session like this occurred during each 1.5 -hour weekly class period, although, DA may have been employed at various other instances by the teacher during the class. In the third and final session, an audio recording of the interactions was recorded without the participants being made aware they were being recorded to prevent any alteration in their responses due to a feeling of being monitored. Although the teacher did visibly take notes on the learners' performance, there was an attempt to make the interactions feel somewhat informal in order to keep the participants from feeling like their abilities were being formally 'assessed' thus causing stress or anxiety which may obstruct their ability to think clearly. This was achieved in physical sense, through seating arrangement. The participants and teacher sat around a table facing each other like a real-world conversation, that is, not with the teacher in a lecture position at the front; with students facing them while seated at an individual desk. Furthermore, the teacher strived to keep the session feeling like a 'light conversation' about the participants daily lives as opposed to a formal classroom activity. In this way, 1) the participant's anxiety level could be curved leading to more natural language output and, 2) the participant can think on a clearer level enabling them to access more of their internal knowledge of the language resulting in more varied responses. After all participants had a chance to respond the class continued with other normally scheduled activities such as, reading, writing, and listening exercises. 


\section{Results}

\subsection{Student-Teacher Interaction}

\begin{tabular}{|c|c|c|c|c|c|c|c|}
\hline Name & $\begin{array}{c}\text { INTRCT. } 1 \\
(\text { session 1) }\end{array}$ & $\begin{array}{c}\text { INTRCT. } 2 \\
(\text { session } 2)\end{array}$ & $\begin{array}{c}\text { INTRCT. } 3 \\
\text { (session 2) }\end{array}$ & $\begin{array}{c}\text { INTRCT. } 4 \\
\text { (session 3) }\end{array}$ & $\begin{array}{l}\text { INTRCT. } 5 \\
\text { (session 3) }\end{array}$ & $\begin{array}{c}\text { INTRCT. } 6 \\
\text { (session 3) }\end{array}$ & $\begin{array}{r}\text { INTRCT. } 7 \\
\text { (session 3) }\end{array}$ \\
\hline Conner & $\begin{array}{c}5 * \text { watch / } \\
\text { watched }\end{array}$ & $2 *$ go / went & $\begin{array}{c}3 * \text { pick / } \\
\text { picked }\end{array}$ & $6 *$ kick / kicked & $6 *$ go / went & & \\
\hline Ginny & $2 *$ do / did & $2 *$ go / went & $2 *$ go / went & $0 *$ go / went & $3 *$ see / saw & $2 *$ see / saw & 0 saw \\
\hline Jack & $6 *$ go / went & $6 *$ is / was & $\begin{array}{c}(\operatorname{session} 3) \\
2 * \text { go / went }\end{array}$ & $6 *$ play / played & & & \\
\hline Mary & $\begin{array}{l}6 * \text { write / } \\
\text { wrote }\end{array}$ & $\begin{array}{c}2 * \text { play / } \\
\text { played }\end{array}$ & $\begin{array}{l}2 * \text { play / } \\
\text { played }\end{array}$ & $\begin{array}{c}0 \text { went } \\
\text { (self-corrected) }\end{array}$ & $\begin{array}{c}0 \text { played } \\
\text { (self-corrected) }\end{array}$ & & \\
\hline
\end{tabular}

Figure 3. Overview of Student - Teacher Interactions

\subsection{Interactions and Potential Development or Regression}

Figure 3 provides an overview of the three interactive sessions, intervention step needed, and the type of error made. The grid shows that over the course of the three sessions, each participant was involved in four to seven interactions with the teacher. Ginny, had the most interactions with 7, followed by Conner and Mary who both had 5, and finally Jack with 4. The number corresponds to the level of intervention need. The asterisk is the original verb form uttered by the student while the correct form the student eventually produced with aid from the teacher is on right side of the forward slash mark. Interaction 1 took place in session 1 , interaction 2 in session 2 (except for Jack's interaction 3) and interactions 4 through 7 all occurred in session 3 . The interactions are listed in a chronological format thus providing a clear picture of development or regression.

The first thing noticed about Conner's interactions is that there is a clear pattern of development toward correct usage of the past-tense forms in interactions 2 and 3 followed by a regression backwards in interactions 4 and 5 . One thing worth pointing out is that the verbs being used in most of Conner's interactions are different every time, which could mean that Conner has not picked up on the pattern of adding -ed to many verbs in English in order to make them past-tense. Another interesting point is that in interaction 2 he is quickly guided to the correct past-tense form of go, however, in the following session, the teacher must go all the way to level 6 in order to elicit to the correct response with a yes/no format (go or went?). Go has an irregular past-tense form (went), meaning students must memorize the form. In interaction 2, Conner needed a little reminding in order to recall the form, however, he seems to have more trouble recalling it in the next session (session 3, interaction 5).

Ginny displays definite signs of development toward an understanding of the target-structure during the course of her interactions with the teacher. During session 2 she used go on two separate interactions, and in both instances the teacher had to repeat the phrase questioningly (level 2 intervention) for her to reach the target - went. Then, in session 3 and without any prompting from the teacher, she is able to produce the correct form. Not only does it seem that she has developed a better awareness of when the past-tense form is needed but also that she has memorized the irregular form, went. This could be explained by the fact that in session 2 she is clearly aware that she needs to use went when an action occurred in the past because she only required a level 2 intervention and, as result, the next time she encountered a situation warranting the use of went she was able to quickly recall her earlier experience. The second example concerning Ginny's development is evidenced in session 3. In this session there are three interactions in which the verb see was used. Like go, see has an irregular past-tense form (saw) indicating that learners must memorize it (e.g. cannot use a generalized rule like adding -ed). In interaction 5 a level 3 intervention is used, followed by a level 2 in interaction 6 . By the third interaction she uses the correct form without any teacher intervention. Because all three of the interactions happened in the same session indicates that the memory of the last two mistakes were probably fresh in her mind allowing her to finally reach the correct form without aid. Again, as in the first example, she relied on her earlier experience to come to the correct answer independent of teacher aid. It is therefore plausible to conclude that some development of her internal processing has taken place because of her needing less and less teacher intervention as specific instances (e.g. go and see) of the target-structure repeatedly occur.

Relative to the other participants, Jack clearly struggles the most with the target-structure. This is evident in two ways. First, an intervention level 6 is needed to reach the correct form of play (played) in interaction 4, which the other participants seem to have a handle on (Mary, session 2, 3, 5; Conner, session 1, 3). It is clear that Jack still needs a lot of assistance from the teacher in order to reach the past-tense form of regular verbs (e.g. verbs ending in -ed such as worked and played). However, though he struggles with the irregular verbs is and go, a decrease in quantity of intervention needed is seen in regards to the verb go. In 
session 1 the teacher provided assistance until level 6, but two weeks later in session 3 , he is able to produce the correct form with just a level 2 prompt. Time between sessions (two weeks) did not seem to be a factor as he seemed aware of the correct form of go / went in session 3, and was able to reach it quickly with less teacher aid, thus a possible indication of development toward the target-structure.

Signs of development are also seen in Mary's performance. In session 1, intervention at level 6 was needed to arrive at the correct form, however, during the next four interactions she showed clear signs of development in both her awareness of when to use past-forms and in recalling the correct form of verbs, whether regular or irregular. In session 2 an intervention of level 2 was needed for her to produce played. This occurred twice in session 2. Then in session 3, held one week later, she at first failed use the past-tense form of play but quickly self-corrected without the teacher's help. Mary again self-corrected when failing to use the past-tense form of $g o$ in interaction 4 of session 3. Both instances may signal a development toward mastery of the target structure because of the quick self-correction. It is evident that some type of increase in cognitive ability took place because of the reduced amount of aid needed to reach the target-structure.

To summarize, there are clear instances of progress toward control over the target structure by each participant during the course of the study. Evidence supporting this claim is the decrease in levels of intervention needed by Ginny, Jack, and Mary in various interactions. Ginny's reliance on teacher aid for the past-tense of go (went) and see (saw) progressed from levels 2-2-0 and 3-2-0. Jack's need for assistance for the verb go (went) decreased from 6 to 2. Mary's progression of 2-2-0 when needing to produce played also shows support for the claim of development toward a mastery of the past-tense form. The one outlier is Conner, who at first seemed to make progress only to regress in the last session. His performance does however align with the idea that development may "be represented not by an exponential line but by "wave-like curves", (Lantolff and Aljaarfreh, 1995, pg. 621). In fact, the levels of intervention required by each participant have been visualized in Figures 4 to 7 below. With the exception of Mary, they all depict "waves"

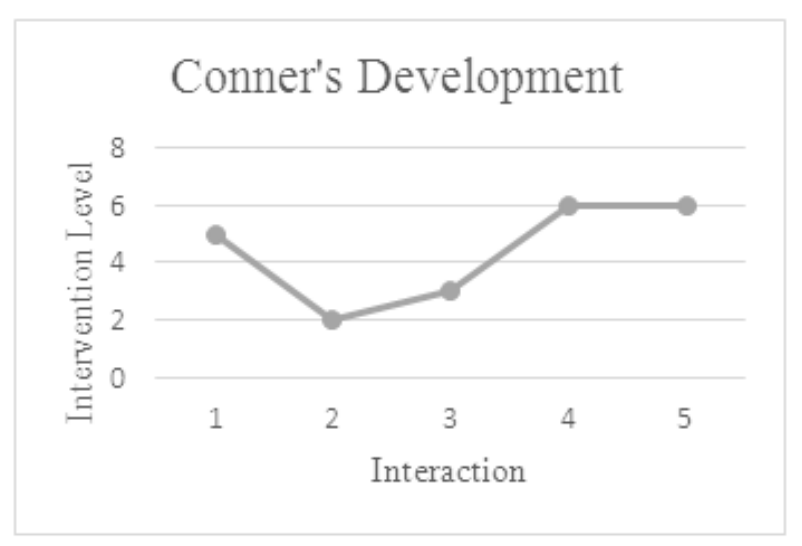

Figure 4

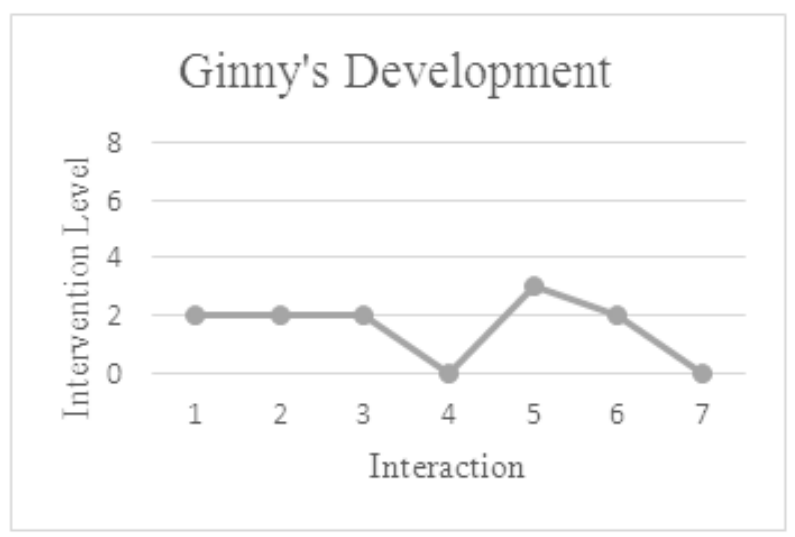

Figure 5

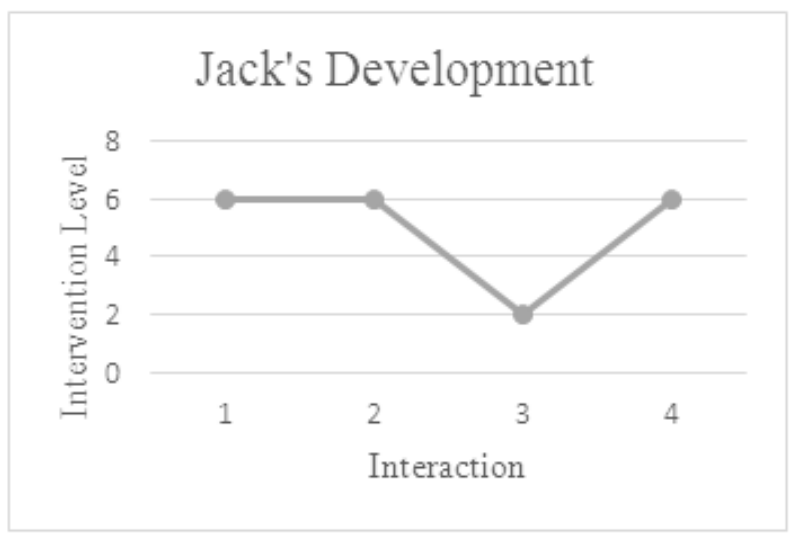

Figure 6 


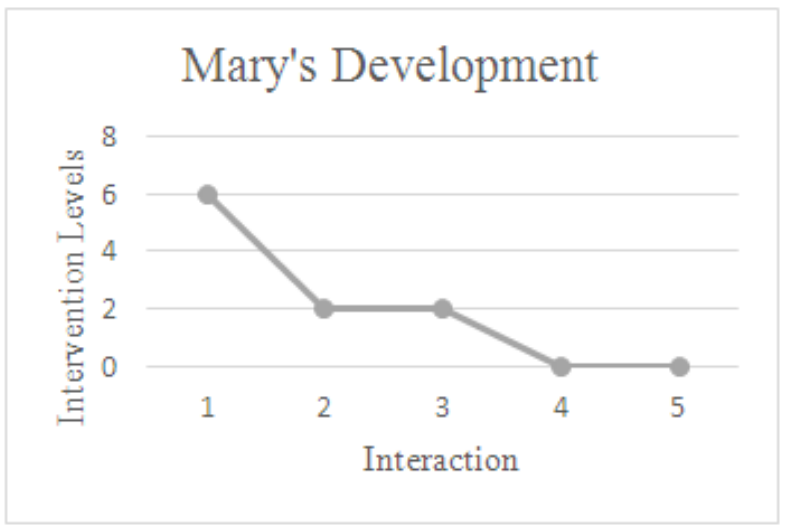

Figure 7

\subsection{Recorded Session 3 Interaction}

To recap, in session 3 participants were asked, "What did you do yesterday?" in order to elicit the target structure, past-tense verbs. As describe earlier, the teacher asked the first student the question and let them respond. The conversation picks up after Conner's response included the incorrect form of the verb kick and prompts 1-4 had already occurred.

Protocol A: Conner and the Teacher (session 3, interaction 4)
T: $\quad$ 1. What's wrong with kick?
C: $\quad$ 2. Student is silent
$\mathrm{T}$ : 3. Is it kicks or kicked?
C: $\quad$ 4. Kick. Kick.
T: $\quad$ 5. Kick yesterday or kicked yesterday.
C: $\quad$ 6. Kicked.
T: $\quad$ 7. Okay, so you kicked the football yesterday.
C: 8. Yeah.

After responding incorrectly, the teacher points out in line 1 that there is a problem with the word kick (level 5 prompt). After a few moments of silence, the teacher moves on to the next prompt (level 6) and gives Conner two possible answers, which then leads him to choose the correct response - kicked.

In the next protocol, the teacher and Mary discuss the same question as Conner. This is Mary's third session and fourth interaction with the teacher and it should be recalled that she has already progressed from levels 6-2-2 in earlier sessions.

Protocol B: Mary and the teacher (session 3, interaction 4)

T: $\quad$ 1. Mary. What did you do yesterday?

M: 2. I... I... Oh! I go to the swimming pool. I went to the swimming pool.

Protocol B shows one of two last interactions with Mary during the study and provides evidence that she requires less prompting than previously as she is now able to self-correct almost instantaneously without intervention from the teacher.

The next protocol is the interaction between the teacher and Ginny. She was posed the same question as the others "What did you do yesterday?".

Protocol C: Ginny and the teacher (session 3, interaction 4)

T: $\quad$ 1. So Ginny, what did you do yesterday?

G: $\quad$ 2. I...I... I went to the...speaks Chinese

$\mathrm{T}$ : $\quad 3$. You went to where?

G: $\quad$ 4. Speaks Chinese

T: 5. What's that? What, what do you do in that place? What do you see?

G: $\quad$ 6. I see peacock.

T: 7. Oh, okay. Wait...you...you see a peacock?

G: $\quad$ 8. I... silence

T: $\quad 9 . \mathrm{See}$ ?

G: 10. I saw.

T: 11. So you saw peacock. And... did you hear the peacock make noise?

G: $\quad$ 12. I don't...I... silence

$\mathrm{T}$ : $\quad$ 13. What noise...what sound does it make?

G: $\quad$ 14. I didn't see peacock because it's too cold. I see $a . .$.

T: 15. I see?

G: $\quad 16$. Oh, I saw the... speaks Chinese

T: $\quad$ 17. A swan?

G: $\quad 18$. I saw the swan. I see the black swan.

This sequence begins with Ginny using the correct form of go (went) in line 2, which she had previously needed prompting at level 2 on two other. This provides evidence that some type of progress has been made in the usage of go / went (prompting at level 2, then 2 again, and now 0 ). In Ginny's next sequence, beginning in line 7, she incorrectly uses see instead of saw. However, after level 2 then level 3 interventions by the teacher in lines 8 and 10 she is quickly able to produce the correct form in line 11. Again, in line 15 she uses see to which the teacher responds with a level 2 prompt leading her to the correct response in line 17. Finally, in line 19 she produces the correct from of see (saw). Interestingly, in the very next sentence she incorrectly reverts back to see. Unfortunately, the teacher did not continue to pursue a correct response because of time limitations and not wanting to correct the student too frequently, possibly causing discouragement.

The final protocol discussed in this paper is one involving Jack. In the first session, the teacher had to use a level 6 prompt in order to produce the correct past-tense verb. In the proceeding interaction, only a level 2 prompt for the same verb was needed.

Protocol D: Jack and the teacher (session 3, interaction 3)

T: $\quad$ 1. Jack, what did you do yesterday?

J: $\quad$ 2. I go to (name of a school)

T: $\quad$ 3. So... wait... you go to (name of a school)?

$\mathrm{J}$ : 4. Went to (name of school)

T: $\quad 5$. You went there... and what did you do? 


\section{J: $\quad$ 6. Speaks Chinese \\ T: 7. Class? \\ J: $\quad$ 8. Go to class. \\ T: $\quad 9$. You go to class? \\ $\mathrm{J}: 10$. Went to class.}

In Protocol D, Jack mistakenly uses the present-simple form $g o$ in his response to the question. However, after the teacher repeats the statement as a question and emphasizes go (level 2 prompt), he is able to use the right form, went. This is a large leap from session 1, in which the teacher had to rephrase it as "go or went?", a more explicit prompt (level 6). However, in a sequence of phrases immediately following Protocol D, Jack shows that he may not have internalized the fact that the past-tense form must be used when the context is in the past. In an ensuing string of sentences (not show here), he again needs to be prompted at level 6 to produce the correct past-tense from - played. It is obvious that he is aware of the correct forms, however, he still needs heavy prompting to reach the right conclusion.

\section{Discussions}

This study uses DA to examine two aspects of the EFL classroom. Firstly, it gave a firsthand account of how an ESL teacher employed DA in their classroom. Secondly, it analyzed the participants' development toward a mastery of past-tense verbs. In the study, the teacher undertook Vygotsky's method of 'praxis', that is, the unification of theory and practice. The methodology used by teacher was neither a one-size-fits-all model nor an exact replica of those used in other study's such as Lantolf and Poehner (2010). Instead, the teacher took the concept of DA and molded it into something that was both appropriate and contextualized to their own classroom environment. This is worth mentioning because it displays the relationship between practice and theory as well as highlight that DA is not a strict procedure of assessment with stringent guidelines that much be adhered to. Instead, it is another way to conceptualize the dynamic interaction between instruction, assessment, and development, which is subject to change based upon needs demanded by the teaching environment.

During the teacher - learner interactions the teacher facilitated development through a list of prompts whose design gives learners the opportunity to actively participate in the interaction as well as realize certain linguistic features of a language in the process. The teacher in this study gave them time and space to produce the target structure before intervening at an appropriate level, and if needed, increase the level of intervention on an implicit / explicit scale until the learner was able to produce the correct response. In doing this, focus was placed not only on the learner's increased performance of the target structure but also on the development of what they can achieve independently as an L2er. This is exemplified through the decreased level of dependence on explicit teacher intervention by Ginny (2-2-0 for went and 3-2-0 for saw) Mary's (2-2-0 for the verb played), and Jack's decrease from level 6 to level 2 intervention to produce the correct past-tense form of go, went. While explicit correction of learners' mistakes may be more efficient for finishing a learning exercise or pointing out errors, DA gives the teacher an opportunity to evaluate learners' mastery of specific linguistic features as well as assess their cognitive development. If a teacher is quick to overtly correct mistakes, it could obscure the learner's grasp of the target structure from the teacher, as well as obstruct the learner's acquisition of the linguistic feature. It is up to the teacher to decide the quantity and frequency of intervention needed during interactions in order to supply an adequate amount of aid. On one hand, a learner's capacity to provide correct responses based on implicit prompts indicates a close proximity to mastery over a target structure and the language itself. On the other hand, dependence on more explicit assistance signifies that a learner is a further distance away from exhibiting control of the language. Mediation by the teacher, both implicit and explicit, can aid in development by assisting learners when they seem unable to move past what they can achieve independent of support from a teacher.

Prior to the study, the teacher concluded that Conner's overall ability was higher than that of Mary, however, viewed through the lens of reliance on DA-based teacher intervention, it is evident that Mary was able to recall and use the correct past-tense form of verbs better than Conner. While Conner did show signs of moving toward a better mastery of past-tense usage in session 2, he actually regressed back to needing a prompt level 6 in the last session. Meanwhile, Mary's pattern of development clearly trended toward increased control of the structure as evident in the interaction grid in Figure 3 and the graph displaying linear progress in Figure 7.

Earlier work by Aljaafreh and Lantolf (1994, p. 480) suggested a gradual linear development in terms of mastering a target feature in L2. However, later work by the Lantolf and Aljaafreh (1995) led them to confirm Vygotsky's claim that development is a non-linear process containing 'spasms' and 'upheavals' (1978, p. 73). Although Mary's pattern of development during the DA-based sessions definitely trended in a positive direction (toward mastery of past-tense verb forms), Conner, Ginny, and Jack all displayed the pattern of 'spasms' and 'upheavals' described by Vygotsky (1979, p. 73) and 'wave-like curves' spoken of by Lantolf, and Aljaafreh (1995, pg. 621). Therefore, while it is possible for a learner to develop as quickly as Mary, it may not be plausible to assume this is a typical occurrence among L2ers given the performance of the other students in this study.

Through the lens of SCT, development varies from 
learner to learner and is highly dependent on the quantity and quality of mediation by an instructor. While some students may experience a steady increase over time; for others it may occur suddenly. Some scholars such as Lightbown (2000, p. 446) are skeptical about the value of individual cases of correction, and instead suggest that corrective intervention is effective if it takes place over a longer period of time. Others, such as Lantolf and Aljaafreh (2010) propose that equally if not more important is the quality of interaction that occurs between a learner and a teacher. To support this claim, they point to Feuerstein's work which has shown instances of shorter DA sessions facilitating learner development. Furthermore, they reference Vygotsky's insistence that cognitive development can occur during short periods of time, referred to as 'microgenesis' by Wertsch (1985, pp. 54-55). Following the views of Vygotsky, Wertsch, Lantolf, and Aljaafreh, this study explains the development of the participant's language abilities as evidence of microgenesis due to the quality of interactions with the teacher which involved more than just overtly correcting the mistake. To reiterate an important aspect of DA, the purpose of the interactions is not just to have the learner produce a correct response, but rather to aid in the development as they work out the correct response on their own. Clear examples of this are seen in Ginny's string of interactions involving the correct usage of saw in interactions 5, 6, and 7 as well as Mary's process of producing the correct form of played in interactions 2, 4, and 5. In both examples, the students' reliance on explicit intervention methods from the teacher decreases further and further until the point where they are able to produce the correct form with no intervention at all.

\section{Conclusion}

In conclusion, it is important to point out that although the current study investigated English past-tense verb forms in an EFL classroom, DA research is not limited to the domain of SLA or linguistics. DA research includes studies on the development of reading and math skills, general intelligence, first language acquisition, and even vocational training (Haywood and Lidz, 2007). Research in the area of SLA has investigated reading comprehension (Kozulin and Garb, 2002), oral language usage (Poehner, 2008, Lantolf and Poehner, 2010), and listening comprehension (Ableeya, 2008). Therefore, the goal of this study is not to makes specific assertions about learner development in the pursuit of mastering English past-tense verb forms, but rather it is aimed at showing how the goal of interactions between teachers and learners in the ZPD is focused on the process of development in itself.

\section{REFERENCES}

[1] Ableeva, R. (2008). The effects of dynamic assessment on L2 listening. In J.P. Lantolf and M.E. Poehner (Eds.), Sociocultural theory and the teaching of second languages (pp. 57-86). London: Equinox.

[2] Aljaafreh, A., \& Lantolf, J. P. (1994). Negative Feedback as Regulation and Second Language Learning in the Zone of Proximal Development. The Modern Language Journal, 78(4), 465-483. doi: 10.1111/j.1540-4781.1994.tb02064.x

[3] Afzaal, M., \& Xiangyi, J. (2020). Book review: Ken Hyland and Feng (Kevin) Jiang, Academic Discourse and Global Publishing: Disciplinary Persuasion in Changing Times. Discourse Studies, 22(3), 384-386. https://doi.org/10.1177/ 1461445620905135

[4] Anning, A., Cullen, J., \& Fleer, M. (2008). Research contexts across cultures. In A. Anning,

[5] J. Cullen, \& M. Fleer (Eds.), Early childhood education: Society and culture (pp. 1-15). London: Sage Publications.

[6] Davison, C., Leung, C., Hill, K., \& Sabet, M. (2009). Dynamic Speaking Assessments. TESOL Quarterly, 43(3), 537-545. doi: 10.1002/j.1545-7249.2009.tb00251.x

[7] Haywood, H.C. \& Lidz, C.S. (2007). Dynamic assessment in practice. Clinical and educational applications. New York: Cambridge University Press.

[8] Hidri, S. (2014). Developing and evaluating a dynamic assessment of listening comprehension in an EFL context. Language Testing in Asia, 4(1). doi: 10.1186/2229-0443-4-4

[9] Kozulin, A., \& Garb, E. (2002). Dynamic Assessment of EFL Text Comprehension. School Psychology International, 23(1), 112-127. doi: 10.1177/0143034302023001733

[10] Lantolf, J. P., \& Aljaafreh, A. (1995). Second language learning in the zone of proximal development: A revolutionary experience. International Journal of Educational Research, 23, 619-632.

[11] Lantolf, J. P. (Ed.). (2000b). Sociocultural theory and second language learning. Oxford University Press.

[12] Lantolf, J. P., \& Poehner, M. E. (2004). Dynamic assessment of L2 development: bringing the past into the future. Journal of Applied Linguistics, 1(1), 49-72. doi: 10.1558/japl.1.1.49.55872

[13] Lantolf, J. P., \& Thorne, S. L. (2006a). Sociocultural theory and second language learning.

[14] In B. VanPatten \& J. Williams (Eds.), Theories in second language acquisition: an introduction (pp. 201-224). Mahwah, NJ: Lawrence Erlbaum Associates.

[15] Lantolf, J. P., \& Poehner, M. E. (2010). Dynamic assessment in the classroom: Vygotskian praxis for second language development. Language Teaching Research, 15(1), 11-33. doi: $10.1177 / 1362168810383328$

[16] Lazarton, A. (2001). Teaching oral skills. In M. Celce-Murcia (Ed.), Teaching English as a second or foreign language (pp. 103-115). Boston, MA: Heinle \& Heinle. 
[17] Leung, C. (2007). Dynamic Assessment: Assessment for and as teaching? Language Assessment Quarterly, 4(3), 257-278. doi:10.1080/15434300701481127

[18] Li, C. N., \& Thompson, S. A. (1989). Mandarin Chinese a functional reference grammar. Berkeley, Calif.: Univ. of California Press.

[19] Lightbown, P.M. (2000). Classroom SLA research and second language teaching. Applied Linguistics, 21, 431-62.

[20] Lightbown, P., \& Spada, N. M. (2006). How languages are learned. Oxford: Oxford University Press.

[21] Miao, T., \& Lv, M. (2012). Dynamic Assessment in ESL writing classroom. 2012 First National Conference for Engineering Sciences (FNCES 2012). doi: 10.1109/nces.2012.6543527

[22] Poehner, M. E., \& Lantolf, J. P. (2005). Dynamic assessment in the language classroom. Language Teaching Research, $9(3), 233-265$.

[23] Poehner, M. E. (2007). Beyond the Test: L2 Dynamic Assessment and the Transcendence of Mediated Learning. The Modern Language Journal, 91(3), 323-340. doi: 10.1111/j.1540-4781.2007.00583.x

[24] Poehner, M.E. (2008). Dynamic assessment: A Vygotskian approach to understanding and promoting second language development. Berlin: Springer.

[25] Poehner, M. E., \& Infante, P. (2016). Mediated Development: A Vygotskian Approach to Transforming Second Language Learner Abilities. TESOL Quarterly, 51(2), 332-357. doi: 10.1002/tesq.308

[26] Shrestha, P., \& Coffin, C. (2012). Dynamic assessment, tutor mediation and academic writing development. Assessing Writing, 17(1), 55-70. doi: 10.1016/j.asw.2011.11.003

[27] Son, G., \& Kim, S. (2017). The Potentials of Dynamic Assessment for the Development of English Speaking Performance: A Microgenetic Analysis. Journal of the Korea English Education Society, 16(1), 47-82. doi: 10.18649/jkees.2017.16.1.47

[28] Vygotsky, L. S. (1978). Mind in society: the development of higher psychological processes. Cambridge, MA: Harvard University Press.

[29] Vygotsky, L. S. (1997). The Historical Meaning of the Crisis in Psychology: A Methodological Investigation. In The Collected Works of L. S. Vygotsky. Vol. 3. Problems of the Theory and History of Psychology (pp. 233-344).. R. W. Rieber \& J. Wollock (Eds.).. New York: Plenum

[30] Wang, P. (2015). The Effect of Dynamic Assessment on the Listening Skills of Lower-intermediate EFL Learners in Chinese Technical College: A Pilot Study. Journal of Language Teaching and Research, 6(6), 1269. doi: $10.17507 /$ jltr.0606.14

[31] Wertsch, J.V. (1985). Vygotsky and the social formation of mind. Cambridge, MA: Harvard University Press.

[32] Yang, S., \& Huang, Y. Y. (2004). The impact of the absence of grammatical tense in L1 on the acquisition of the tense-aspect system in L2. IRAL - International Review of Applied Linguistics in Language Teaching, 42(1). doi: 10.1515/iral.2004.002

[33] Yang, Y., \& Qian, D. D. (2017). Assessing English reading comprehension by Chinese EFL learners in computerized dynamic assessment. Language Testing in Asia, 7(1). doi: 10.1186/s40468-017-0042-3 